\title{
THE EUROPEAN RESEARCH INFRASTRUCTURE FOR HERITAGE SCIENCE (E- RIHS)
}

\author{
J. Striova ${ }^{\text {a }}$ L. Pezzati ${ }^{\text {a* }}$ \\ ${ }^{a}$ National Institute of Optics, National Research Council, Largo Fermi 6, 50125 Florence, Italy \\ jana.striova@ino.it \\ luca.pezzati@cnr.it
}

Commission II, WG II/4

KEY WORDS: Research Infrastructures, Heritage Science, MOLAB

\begin{abstract}
:
The European Research Infrastructure for Heritage Science (E-RIHS) entered the European strategic roadmap for research infrastructures (ESFRI Roadmap [1]) in 2016, as one of its six new projects. E-RIHS supports research on heritage interpretation, preservation, documentation and management. Both cultural and natural heritage are addressed: collections, artworks, buildings, monuments and archaeological sites. E-RIHS aims to become a distributed research infrastructure with a multi-level star-structure: facilities from single Countries will be organized in national nodes, coordinated by National Hubs. The E-RIHS Central Hub will provide the unique access point to all E-RIHS services through coordination of National Hubs. E-RIHS activities already started in some of its national nodes. In Italy the access to some E-RIHS services started in 2015. A case study concerning the diagnostic of a hypogea cave is presented.
\end{abstract}

\section{INTRODUCTION}

Tangible cultural and natural heritage are key components of the European identity. The study and preservation of cultural and natural heritage is a global challenge for science and the European society. The European Research Infrastructure for Heritage Science (E-RIHS) supports research on heritage interpretation, preservation, documentation and management. Cross-disciplinary groups of researchers will provide state-ofthe-art tools and services to cross-disciplinary users and scientific communities working to advance knowledge about heritage and to devise innovative strategies for its preservation. E-RIHS connects researchers in the humanities and natural sciences and fosters a trans-disciplinary culture of exchange and cooperation. E-RIHS pursues the integration of European excellent facilities to create a cohesive entity playing a connecting role in the global community of heritage science.

\subsection{Access platforms}

E-RIHS will provide state-of-the-art tools and services to crossdisciplinary research communities of users through its four access platforms:

1. MOLAB: access to advanced mobile analytical instrumentation for diagnostics of heritage objects, archaeological sites and historical monuments. The MObile LABoratories will allow its users to carry out complex multi-technique diagnostic projects, allowing effective in situ investigation.

2. FIXLAB: access to large-scale and specific facilities with unique expertise in heritage science, for cuttingedge scientific investigation on samples or whole objects, revealing micro-structures and chemical composition, giving essential and invaluable insights into historical technologies, materials and species, their context, chronologies, alteration and degradation phenomena.

3. ARCHLAB: physical access to archives and collections of prestigious European museums, galleries, research institutions and universities containing non-digital samples and specimens and organized scientific information.

4. DIGILAB: virtual access to tools and data hubs for heritage research - including measurement results, analytical data and documentation - from large academic as well as research and heritage institutions.

\section{E-RIHS PREPARATORY PHASE}

E-RIHS is focused on the preservation of the World's Heritage by enabling cutting-edge research in heritage science, liaising with governments and heritage institutions to promote its constant development and, finally, raising the appreciation of the large public for cultural and natural heritage and the recognition of its historic, social and economic significance. The E-RIHS's goal is also the promotion and harmonization of joint research activities in heritage science (HS), provision of advanced training to HS researchers and students, dissemination and exploitation of research results, and contribution to knowledge transfer and researchers mobility.

The proposal for establishing a GRI [Global Research Infrastructure] based on the E-RIHS partnership was submitted to the GSO [2] by Italy in 2014. An international initiative will be carried on in parallel with the preparatory phase of E-RIHS for connecting and including partners and facilities outside EU, gradually reaching the status of a global distributed research infrastructure of which E-RIHS could be the leading scientific partner. E-RIHS is collaborating on this roadmap with the intergovernmental organization ICCROM [3].

* Corresponding author 
E-RIHS started, in February 2017, its preparatory phase supported by the EU project E-RIHS PP (H2020-INFRADEV02-2016). E-RIHS is a pan-European distributed infrastructure supported by 15 Member States plus Israel and participated by six more EU and associated countries.

E-RIHS star-design structure has its Central Hub and headquarters in Florence (IT) and comprises National Hubs possibly organised in Regional Hubs in some countries encompassing specialised knowledge, fixed and mobile nationa facilities of recognized excellence, physically accessible collections/archives and remotely accessible heritage data Representatives of twenty one Countries plus three international organizations are now working together to prepare E-RIHS to be launched as a standalone European Research Infrastructure Consortium (ERIC) in 2021

\section{E-RIHS ITALIAN NODE}

\subsection{National activities}

The Italian hub, E-RIHS.it, is currently structuring the governance and coordination of the E-RIHS national node. Up to now, the E-RIHS access services have been operated at the national level thanks to the E-RIHS.it project under the coordination of National Research Council (CNR), receiving an average $€ 400,000$ annual funding from the Ministry of Education, University and Research (MIUR). The first Pilot call for the access to mobile national laboratories of E-RIHS.it was launched in 2015. Following an international peer review process, seven access projects were selected and carried out.

\subsection{Project DiaCavHE}

In the competitive selection procedure, the project DiaCavHE (Save Rocks and Colours: A Code of Conduct for a "Context Diagnostic" of Cave Heritage) lead by Manuela de Giorgi (University of Salento) has been approved. The ultimate goal of this research project has been to define a model diagnostic approach to hypogean churches, which are rather common especially in defined areas of southern Italy. The cave church Sant'Angelo in Casalrotto (Mottola-Taranto, Italy), with extensive wall paintings has been the object of the study [4-7] The MOBile LABoratory (MOLAB) has been called for the characterization of the painting technique, of pigments composition, of the state of conservation of the cave church and, finally, for its 3D modelling. The church of Sant'Angelo (Fig. 1) is an unique object, being the only rock church on the whole national territory to be structured on two levels (Fig. 2), with the upper church serving the liturgy and the lower one used for funerary function, as evidenced by the presence of single deposited medieval tombs (Fig. 3). From a planimetric point of view, the lower church, smaller than the upper one, is more organic, conceived according to a unitary architectural criterion and in a narrower temporal space with three naves are divided by two monolithic pillars. The space was probably also used for worship, but mainly served as funerary crypt, supported by the indisputable testimony of tombs dug and lined up on the floor.

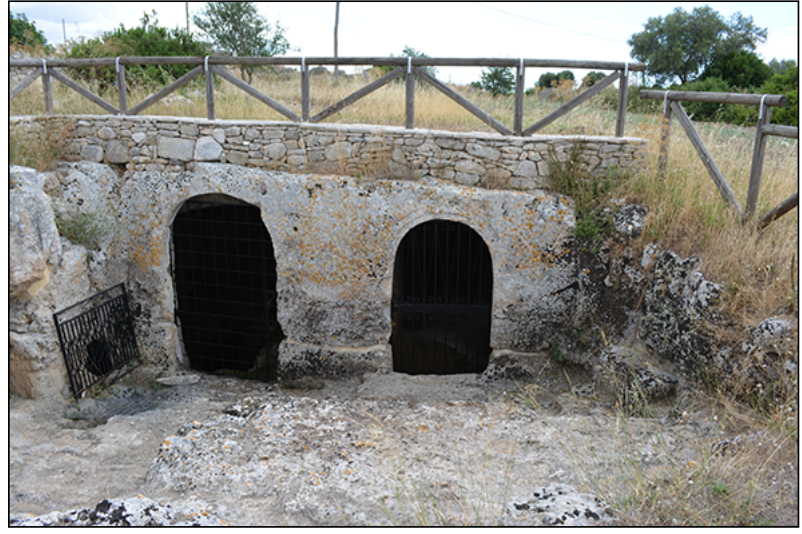

Figure 1. Entrance to the cave church Sant'Angelo

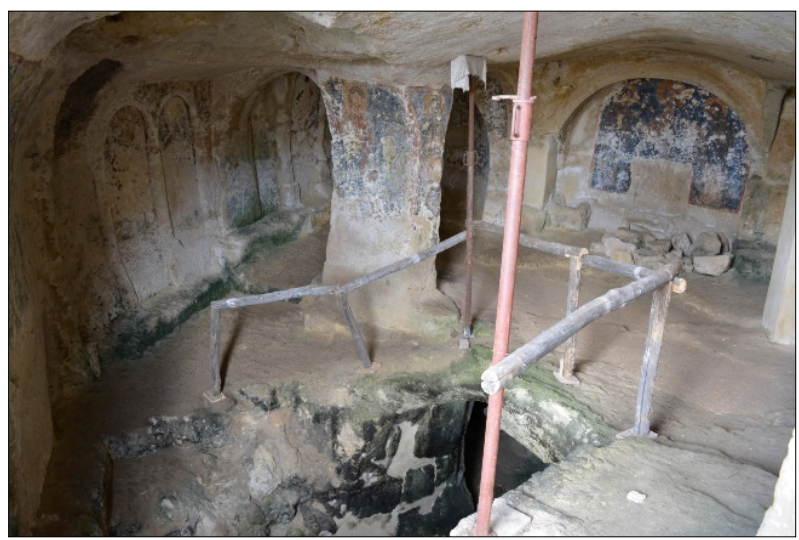

Figure 2. Upper level of the church - central apse and entrance the lower level.

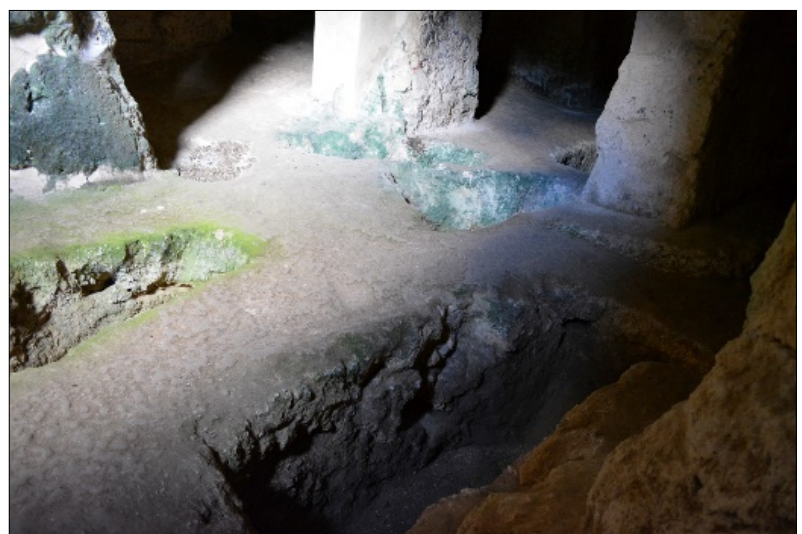

Figure 3. Lower level of the church - tombs.

The iconographic pattern recalls the middle-Byzantine monastic plan of the cross, inscribed in a square, with three oriented apses. The parietal pictorial decoration, which originally covered the church interior entirely, is now preserved in some fragments, significant in the area of the apses and along the side of the counter facade, and scattered in other parts. The dating of the pictorial palimpsests spans from the late XII to XIV century. 
In this hypogean context, several Institutes of the National Research Council were involved to intervene with state-of-theart MOLAB techniques: X-ray fluorescence (Institute of Molecular Science and Technologies, ISTM) for identification of pigments; Ion Chromatography (Institute of Archaeological and Monumental Heritage, IBAM) for analysis of soluble salts and portable microscope for ultraviolet-induced multispectral fluorescence (developed by National Institute of Optics, INO) to map presence of patinas of organic origin (lichens and fungi) (Fig. 4).

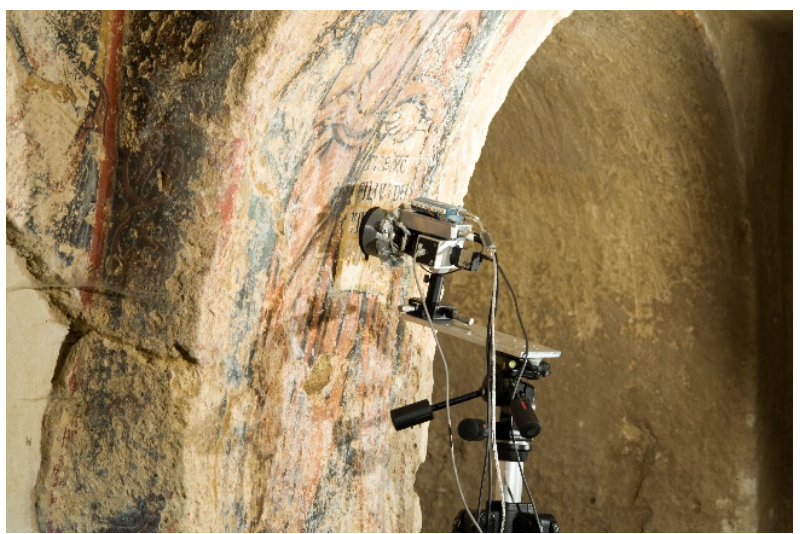

Figure 4. Mapping of organic contaminants with portable UV multispectral fluorescence microscope.

The Time of Flight Laser Scanning (Institute of Information Science and Technologies, ISTI) served for the reconstruction of the 3D model (Fig. 5). To scan the two planes of the church, 16 scans were obtained on the upper floor and 9 scans on the lower floor, each single scan containing approximately 6.5 million 3D points. It was necessary to resume the structure from different observation points in order to complete sampling of the inner surface. The high number of shooting positions is due to the particular architectural structure of the church, where the presence of columns, pillars and arches inside spaces and niches has made it extremely difficult to select an optimal set of shooting positions. In addition, 4 scans were also made of the outside of the entrance in order to have data also on the external entry area of the artefact.

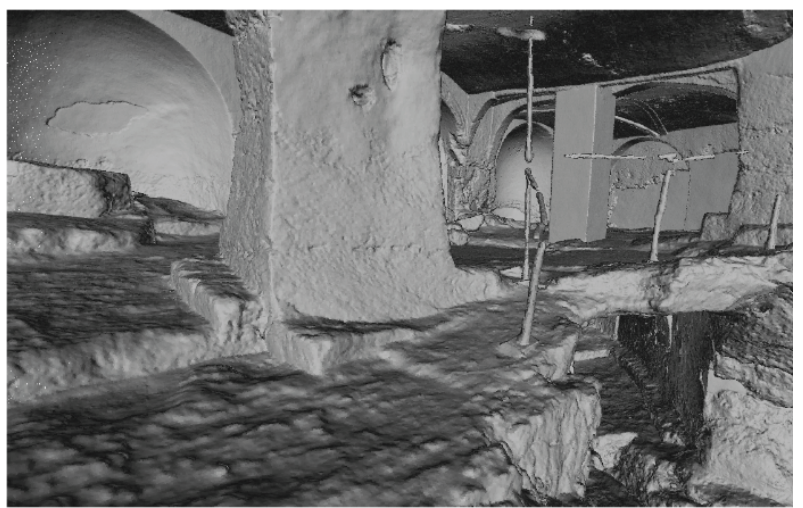

Figure 5. The global 3D model obtained after the fusion phase of single shots (complexity of $50 \mathrm{M}$ triangles, model density about 1 point per $5 \mathrm{~mm}$ ).

The model thus obtained has been simplified (controlled reduction of geometric complexity) to produce a version of 20 million triangles, on which the colour obtained from 170 photos (each 24 Mpix) was mapped (Fig. 7). Among the frescoes present, three were selected, for which high resolution images were used.

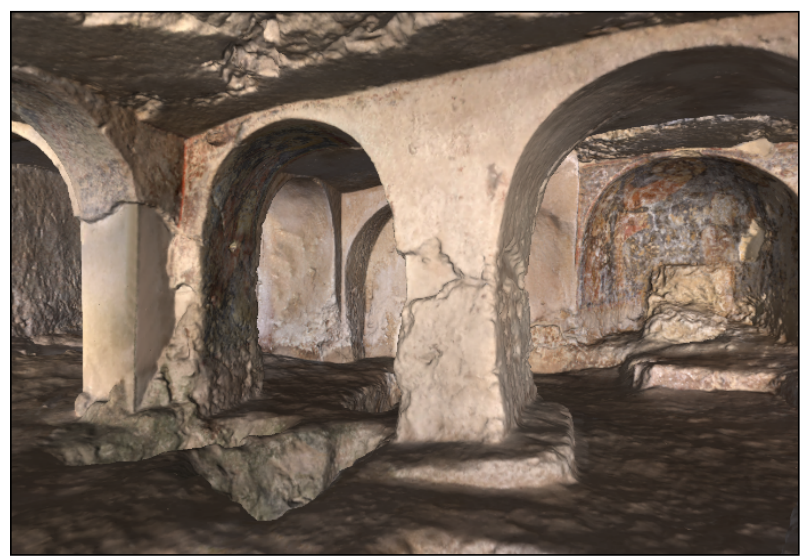

Figure 6. 3D model with mapped colour for the fruition of the church interior.

The phenomenon of the rocky civilization assumes, in medieval era, a role of great relevance in artistic expression of southern Italy. The results provided by the access to E-RIHS.it MOLAB facilities lead to conclusions that the hypogeum presents two different conservative profiles, referable to the architectural structure and to parietal decorations. The first connotes for a widespread shallow cracking of the rock that however currently does not affect the static the building, neither signals of possible rock slips that would compromise the object usability. The performed analyses contributed to the understanding and mainly mapping of some degradation phenomena and mechanisms providing at the same time $3 \mathrm{D}$ models, which will be made available on the web through the 3DHop tool developed by the Visual Computing Lab of ISTI for the remote fruition of the artefact.

\section{CONCLUSION}

E-RIHS access to mobile instrumentation through its MOLAB platform, currently accessible for researchers by applying to the EU integrating activity project IPERION $\mathrm{CH}$ (www.iperionch.eu), provides unique tools for gathering new knowledge on heritage data where inaccessible or immovable heritage is to be studied. Along with the analytic measurements from the FIXLAB platform, the acquired new knowledge will be made usable in the DIGILAB, where it will be stored for documentation and for future research needs.

\section{ACKNOWLEDGEMENTS}

We thank Manuela De Giorgi for allowing the use of the iconographic materials of project DiaCavHe. Thanks to the Visual Computing Group of ISTI-CNR, lead by Roberto Scopigno, for the use of the images of the 3D model.

\section{REFERENCES}

[1] The Roadmap ESFRI-European Strategy Forum on Research Infrastructures is a long-term plan adopted by the European Commission listing the research infrastructures which are considered to be strategic for the development of European research in all scientific domains. 
[2] The GSO (Group of Senior Officials) was instituted by the Carnegie Group of G7 Science Advisors. In 2013 the GSO proposed a Framework for Global Research Infrastructures. It is now composed by government representatives from the $\mathrm{G} 7+5$ Countries.

[3] The International Centre for the Study of the Preservation and Restoration of Cultural Property, ICCROM (http://www.iccrom.org) is a intergovernmental organization created by UNESCO in 1956. ICCROM headquarters are in Rome.

[4] Le aree rupestri dell'Italia centro-meridionale nell'ambito delle civiltà italiche: conoscenza, salvaguardia, tutela, Atti del IV Convegno internazionale sulla civiltà rupestre (Savelletri di Fasano, 2009), Spoleto, 2011;

[5] F. Zezza, Analisi del degrado delle pitture rupestri in grotta, in Atti del Convegno internazionale sulla civiltà rupestre "Quando abitavamo in grotta" (Savelletri di Fasano, 2003), Spoleto, 2004, pp. 61- 82;

[6] F. dell'Aquila, A. Messina, Le chiese rupestri di Puglia e Basilicata, Bari 1998, p. 222

[7] M. Falla Castelfranchi, Pittura monumentale bizantina in Puglia, Milano 1991 